\title{
Autoantikörper gegen Nebenschilddrüse
}

\author{
W. Stöcker \\ Euroimmun Medizinische Labordiagnostika AG, Lübeck, \\ Deutschland
}

Synonym(e) Autoantikörper gegen Epithelkörperchen; Nebenschilddrüsen-Antikörper

Englischer Begriff parathyroid gland autoantibodies

Definition Autoantikörper gegen Nebenschilddrüse kommen bei idiopathischem Hypoparathyreoidismus und in Kombination mit anderen Autoantikörpern auch bei Polyendokrinopathie vor.

Funktion - Pathophysiologie Bei einem Teil der Patienten mit idiopathischem Hypoparathyreoidismus findet man im Serum Autoantikörper (überwiegend der Klasse IgG) gegen die Nebenschilddrüse. Das Vorliegen dieser Antikörper belegt die Autoimmunpathogenese bei diesen Patienten, kann aber auch Hinweis auf eine Autoimmunpolyendokrinopathie sein.

\section{Untersuchungsmaterial Serum.}

Probenstabilität Autoantikörper sind bei $+4{ }^{\circ} \mathrm{C}$ bis $\mathrm{zu}$ 2 Wochen lang beständig, bei $-20{ }^{\circ} \mathrm{C}$ über Monate und Jahre hinweg.

Analytik Zum Nachweis der Autoantikörper gegen Zellen der Nebenschilddrüse durch indirekte Immunfluoreszenz ( $>$ Immunfluoreszenz, indirekte) werden Gefrierschnitte der Glandula parathyreoidea von Primaten als Standardsubstrat verwendet. Bei einem positiven Ergebnis zeigen die Hauptzellen und (hervorgehoben) die oxyphilen Zellen der Nebenschilddrüse eine glatte bis feingranuläre Fluoreszenz (s. Abbildung; Substrat Nebenschilddrüse von Primaten):

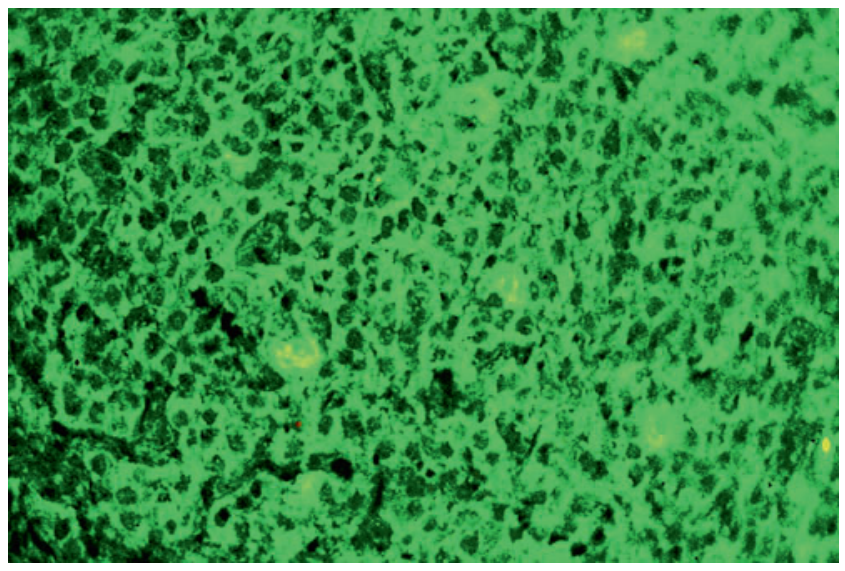

Mit einer parallel eingesetzten Rattenniere erfolgt eine sichere Abgrenzung zum $>$ Autoantikörper gegen Mitochondrien (AMA).

Als Antigensubstrat eignet sich humanes Adenomgewebe, dessen Funktionsfähigkeit allerdings zuerst mit positiven Patientenseren und einer ausreichenden Anzahl negativer Kontrollen überprüft werden muss.

\section{Referenzbereich - Erwachsene Negativ.}

Referenzbereich - Kinder Negativ.

Interpretation Antikörper gegen die Nebenschilddrüse weisen auf einen idiopathischen Hypoparathyreoidismus hin, gegebenenfalls in Verbindung mit einer Autoimmunpolyendokrinopathie Typ I (Hypoparathyreoidismus, Nebennierenrindeninsuffizienz und perniziöse Anämie sowie mukokutane Kandidiasis).

\section{Literatur}

Eisenbarth GS, Gottlieb PA (2004) Autoimmune polyendocrine syndromes. N Engl J Med 350:2068-2079 